\title{
UMA LEITURA FREUDIANA DA CATEGORIA DE IDENTIDADE EM ANTHONY GIDDENS
}

Eduardo Leal Cunha

Doutor em Saúde Coletiva (IMS/Uerj); professor adjunto da Universidade Federal de Sergipe.
RESUMO: Pretende-se examinar as formulações de Anthony Giddens sobre a categoria de identidade, em especial na sua articulação com a experiência da modernidade. Procura-se indicar como tais formulações implicam um modo de apreensão da experiência subjetiva que pode ser posto em questão pela teoria psicanalítica, especialmente a partir da categoria de sujeito, nas suas relações com a razão e a consciência. Compara-se com algumas proposições freudianas em torno da idéia de eu e do seu lugar na formação do aparato psíquico.

Palavras-chave: Identidade, modernidade, eu, sujeito.

ABSTRACT: A Freudian reading of the category of identity in Anthony Giddens. This article intends to examine the formulations made by Anthony Giddens about the category of identity, specially in its articulations with the experience of modernity, and it tries to indicate in which ways such formulations imply a modality of apprehension of the subjective experience which may be questioned by the psychoanalytical theory, specially starting from a consideration of the category of subject, in its relations with reason and consciousness, and from some Freudian propositions about the idea of Ego and its place in the constitution of the psychic apparatus. Keywords: Identity, modernity, ego, subject.

$\mathrm{E}$ m 1968, Erik Erikson, ao introduzir o seu clássico trabalho sobre a identidade, afirma que é "chegado o momento de proceder a uma melhor e final delimitação do que é e do que não é identidade" (ERIKSON, 1987, p.13). Mais de 30 anos depois, no entanto, o termo ainda parece estranho ao pensamento psicanalítico e disso nos dá testemunho, por exemplo, sua ausência dos principais dicionários de psicanálise. ${ }^{1}$ Neles,

${ }^{1}$ Ver, por exemplo: Roudinesco \& Plon (1998); Kaufmann (1996); Chemama (1995); Laplanche \& Pontalis (1982). 
aparece apenas de modo transversal, por meio da categoria de identidade sexual e vinculado a uma discussão sobre gênero que se dá nas fronteiras entre a teoria psicanalítica, a biologia, a sexologia e a medicina. Tal ausência, vale ressaltar, se contrapõe ao que pode ser descrito como onipresença da categoria de identidade no pensamento contemporâneo.

"A identidade tornou-se um prisma através do qual os outros aspectos da vida contemporânea são compreendidos e examinados. Assim, o debate sobre a justiça e a igualdade tende a ser conduzido em termos de 'reconhecimento' de identidade; falamos de cultura em termos de identidades diferentes com seu hibridismo e 'creolização' - enquanto o processo político é ainda e mais freqüentemente teorizado em torno dos problemas dos direitos do homem (o direito a uma identidade separada) e das políticas de vida (a construção, a negociação e a afirmação da identidade)." (BAUMAN, 2002, p.55)

Ou seja, a despeito da sua presença maciça na cultura e mesmo na política, registra-se um silêncio em torno da noção de identidade ${ }^{2}$ no pensamento psicanalítico, ainda que o campo problemático em que tal noção se insere, que diz respeito aos modos de enunciação da experiência subjetiva e à relação consigo mesmo e com o outro, não possa ser negligenciado ou ignorado. Pois mesmo que a invenção freudiana ponha em questão os termos da interrogação "quem sou eu?", acreditamos que não podemos desqualificar tal pergunta nem tampouco ignorar os modos como ela pode ser respondida ou ainda as formas como as possíveis respostas se articulam aos diversos tipos de sofrimento psíquico que marcam a atualidade. Essa decerto é a principal justificativa para nosso interesse pela perspectiva identitária, a qual em nossa sociedade aparece como resposta hegemônica a essa interrogação na qual se tecem o "quem" e o "eu".

Partimos desse estranhamento e desse silêncio para pensar como se revela de fato aí algo da ordem do estranho (FREUD, 1919/1999), em que o efeito de horror é produzido precisamente pelo retorno no exterior, no campo do fora, de algo que, sendo da ordem do recalcado, revela o que temos de íntimo e para o que não encontramos, ou não podemos encontrar, palavras. Desta forma, talvez seja possível discutir quais seriam as formas outras de elaboração do que há de inquietante em torno da problemática identitária, tanto na teoria quanto na clínica. Se a idéia de identidade aparece no mundo contemporâneo como o modelo hegemônico de resposta à questão da construção de si e do posicionamento no mundo, bases necessárias e definidoras dos modos de relação com o outro, nos cabe perguntar em que medida tal modelo pode ser legitimado ou questionado pela teoria psicanalítica.

\footnotetext{
${ }^{2}$ A propósito da presença da noção de identidade na obra de Freud, ver Cunha (2000).
} 
Dessa maneira, procuraremos estabelecer de início uma crítica do que denominamos 'perspectiva identitária', representada aqui pelas formulações de Anthony Giddens, para, em seguida, discutir não apenas como tal perspectiva pode ser tomada criticamente pela psicanálise, mas, sobretudo, como a lógica das identidades, na medida que se coloca como forma hegemônica de relação consigo mesmo, centrada na construção de uma inteligibilidade sobre si, apoiada em valores como previsibilidade e controle, portanto vinculada a um sujeito da razão e da consciência, pode pôr em questão certas formulações centrais ao pensamento psicanalítico, como a existência de uma dimensão inconsciente do eu, e inviabilizar determinadas direções para a clínica, por exemplo, a valorização do trabalho de produção de fantasias.

Reconhecendo as dificuldades que o uso da noção de identidade nos coloca na atualidade e que se presentificam também no campo das ciências sociais, tornando-a, nos termos de Stuart Hall, um conceito "demasiadamente complexo, muito pouco desenvolvido e muito pouco compreendido" (HALL, 2003, p.8), recorreremos de forma breve a uma leitura crítica da obra do sociólogo Anthony Giddens em torno da identidade no mundo contemporâneo. Nela se estabelece, exatamente para dar conta dessas dificuldades, uma tessitura entre os modos de funcionamento institucional das sociedades modernas e a vida dos indivíduos que habitam tais sociedades (GIDDENS, 2002).

O estudo das proposições do sociólogo britânico, um dos pais da "nova sociologia”, se justifica não só pela posição privilegiada que este ocupa no pensamento sociológico contemporâneo, em especial no estudo das relações entre a experiência subjetiva individual e os modos de organização social a partir da modernidade, no qual noções como a de reflexividade e de mecanismos de desencaixe produziram grande repercussão, mas por ele ter dedicado seus últimos trabalhos à discussão da problemática identitária, estabelecendo uma conceituação de identidade que não apenas é rigorosa do ponto de vista teórico, como descreve de modo bastante preciso o modo como cada um de nós vive a experiência da identidade no cotidiano, contribuindo assim para consolidar certa leitura da experiência subjetiva que assume um lugar hegemônico na atualidade e repercute também na compreensão das novas formas de sofrimento psíquico, o que, obviamente exerce certo impacto sobre a própria clínica psicanalítica. É interessante destacar, ainda, o fato de que em sua teorização sobre a identidade, Giddens recorre de modo significativo a autores do campo psicanalítico, especialmente os da tradição anglo-saxã.

\section{A IDENTIDADE COMO NARRATIVA DO EU}

Em Giddens, a identidade é definida como uma narrativa reflexiva do eu e aparece no contexto de uma leitura do impacto causado pelas transformações da modernida- 
de na experiência individual, como uma articulação, portanto, entre a experiência subjetiva e os modos de organização social (GIDDENS, 2002). Tal forma narrativa teria como funções básicas estabelecer no campo da subjetividade a continuidade entre passado, presente e futuro e garantir a integridade psicológica, bem como o mínimo de segurança ontológica que permite enfrentar o contexto de risco e a sensação de insegurança que caracterizam o mundo atual.

O foco da sua argumentação pode ser encontrado na proposição de que, sob um ponto de vista sociológico, no registro subjetivo e na vida cotidiana dos indivíduos, as mudanças provocadas pelos grandes eixos da transformação moderna - como o industrialismo, o capitalismo, a expansão colonial e a experiência da vida burguesa - fizeram-se representar, sobretudo, pela separação entre tempo e espaço, e pela dissolução do que o autor considera os quatro contextos de confiança que caracterizavam as sociedades pré-modernas, a saber: a comunidade, estabelecida e definida por um lugar; as relações de parentesco; a tradição; as cosmologias religiosas (GIDDENS, 1991). Foram tais mudanças que colocaram no centro da nossa experiência o sentimento de risco que, no pensamento de Giddens, aparece como marca característica do homem contemporâneo.

Por isso mesmo, é com esse autor que podemos perceber de modo bastante claro como a perspectiva identitária se vincula diretamente à experiência moderna, que aqui se refere não apenas a um período histórico, mas a um modo específico de organização social que tem como correlato necessário determinado modo de pensar que funda, por sua vez, uma compreensão particular do mundo e da natureza, definindo assim o posicionamento do homem não apenas diante desse mundo e dessa natureza, mas também frente a si mesmo e ao outro.

$\mathrm{Na}$ passagem das sociedades tradicionais para as sociedades modernas, sobretudo a partir do século XVIII, com a formação dos Estados-nação — forma moderna de governo e instância de soberania que aparece como correlata da instalação do indivíduo como valor no centro da organização social (DUMONT, 2000) —, Giddens localiza a separação entre tempo e espaço, contraponto e condição necessária do aparecimento das operações de desencaixe e reencaixe que permitem a fragmentação, deslocamento e compressão das relações entre tempo e espaço, fazendo com que eventos e relações sejam retirados de seus contextos iniciais, locais, para serem então reinseridos em outros contextos.

"O dinamismo da modernidade deriva da separação do tempo e do espaço e de sua recombinação em formas que permitem o 'zoneamento' tempo-espacial preciso da vida social; do desencaixe dos sistemas sociais; e da ordenação e reordenação reflexiva das relações sociais à luz das contínuas entradas (inputs) de conhecimento afetando as ações de indivíduos e grupos. [...] Por desencaixe me refiro ao 'deslo- 
camento' das relações sociais de contextos locais de interação e sua reestruturação através de extensões indefinidas de tempo espaço.” (GIDDENS, 1991, p.25-29)

É em função da separação entre as experiências do tempo e do espaço que ocorre o esvaziamento da categoria de lugar, base de apoio e materialização da experiência da comunidade e, portanto, ponto de ancoragem dos posicionamentos subjetivos nas sociedades ditas tradicionais. O lugar se torna fantasmagórico, ao mesmo tempo que os contextos de confiança que nele se faziam presentes se dissolvem, tornando necessária sua substituição por outras modalidades de agenciamento subjetivo (GIDDENS, 1991).

Em um mundo onde deslocamentos espaciais podem não corresponder à passagem temporal e as relações inter-humanas passam a se dar em contextos de ausência e não de presença, a confiança deixa de ser referida à tradição ou aos sistemas religiosos, para se vincular ao que o autor denomina sistemas abstratos, que são os sistemas peritos, materializados nas novas disciplinas científicas, e as fichas simbólicas, cujo modelo paradigmático é o dinheiro.

Assim, a confiança se desloca das antigas instâncias de garantia para os sistemas abstratos, tornando-se referida ao conhecimento adquirido e à capacidade de previsão dos eventos futuros. O projeto moderno de transformação da natureza se desdobra na busca de previsibilidade e controle dos eventos naturais e humanos. O conhecimento sobre os eventos do mundo e sobre si mesmo se torna então o eixo da relação do homem consigo mesmo, com seus semelhantes e com o mundo à sua volta, fazendo com que entre em cena, nesse trabalho narrativo que resultará na enunciação de uma identidade, a reflexividade, o modo como os indivíduos incorporam de modo contínuo, sob as mais diversas formas, o conhecimento produzido pelos sistemas peritos, estes, por sua vez, também permanentemente retroalimentados pelas ações dos indivíduos.

“Hoje em dia, o eu é para todos um projeto reflexivo — uma interrogação mais ou menos contínua do passado, do presente e do futuro. É um projeto conduzido em meio a uma profusão de recursos reflexivos: terapia e manuais de auto-ajuda de todo os tipos, programas de televisão e artigos de revistas.” (GIDDENS, 1993, p.41)

Dessa forma, o posicionamento no mundo, que aqui nessa perspectiva se articula à enunciação e reconhecimento de uma identidade, já não é dado pela tradição, por exemplo, mas se torna algo a ser construído, uma tarefa de ordenamento, estruturada por meio da produção de uma narrativa linear que encadeie passado, presente e futuro e possibilite ao indivíduo integridade, unicidade e permanência, ao mesmo tempo que lhe garanta segurança ontológica, condição básica para seguir em frente, em especial naquelas situações nas quais o conhe- 
cimento falha e a previsibilidade torna-se incerta, situações que escapam ao controle do indivíduo, sobretudo no que Giddens define como contextos de ausência e compromissos sem rosto (GIDDENS, 2002).

Nesse contexto, a idéia de risco, típica da modernidade, que substitui de certo modo a categoria de perigo, implica ao menos um determinado nível de conhecimento da situação ameaçadora e alguma possibilidade de controle dessa ameaça, ou seja, um domínio relativo da situação. Por conseqüência, para o homem moderno, numa situação de risco, a confiança pressupõe a consciência desse risco e o cálculo das probabilidades de êxito ou fracasso. Ao contrário da crença ou da fé, a confiança moderna — ancorada nos chamados sistemas abstratos - envolverá sempre o máximo de consciência da situação vivida, o maior nível de informação possível sobre a situação e o contexto, o reconhecimento dos limites dessa informação ou da capacidade de ação e algum nível de decisão sobre as alternativas de ação.

O que estamos destacando aqui é como, a partir das proposições de Giddens, o risco se vincula a uma perda de controle, a uma falha nos sistemas desenvolvidos - reflexivamente - para controlar a natureza, ou mesmo o outro, que nos aparece como ameaça. A confiança, segundo Giddens, é necessária quando há ignorância, quando determinados elementos da situação vivida como de risco são desconhecidos e estão assim fora do alcance da nossa ação e, portanto, do nosso controle. É nesse momento que os sistemas abstratos aparecem como instância de garantia, na medida que, pretensamente, reúnem o conhecimento necessário para que o dito controle da situação seja restabelecido. Por meio dos sistemas abstratos, a confiança e o controle passam a se equivaler na busca da segurança e, nesse sentido, ganha relevância outra idéia fundamental para a experiência moderna que é a de escolha, de decisão consciente e racional, livre de paixão, prova imediata da referida capacidade de controle sobre os eventos com vistas ao cumprimento de determinada meta futura.

“Chamo de perfil de risco um elenco específico de ameaças ou perigos característicos da vida social moderna... O risco e o perigo, como vivenciados em relação à segurança ontológica, tornaram-se secularizados juntamente com a maior parte dos outros aspectos da vida social. Um mundo estruturado principalmente por riscos humanamente criados tem muito pouco lugar para influências divinas, ou de fato para as propiciações mágicas de forças ou espíritos cósmicos. É central para a modernidade que os riscos podem ser em princípio avaliados em termos de conhecimento generalizável sobre perigos potenciais.” (GIDDENS, 2002, p.112)

Diante dessas situações, torna-se necessário pensar em um sentimento básico de confiança que funcione como uma espécie de inoculação emocional e permita 
ao indivíduo seguir em frente mesmo que não tenha as respostas das quais em princípio precisaria para orientar de forma correta sua ação no mundo. A confiança deve aparecer onde o conhecimento falha, mas, como veremos, ela será ainda uma aposta na previsibilidade e no controle, e assim, portanto, fundada em certa inteligibilidade do mundo, de si mesmo e do outro.

É para dar conta da formação no desenvolvimento individual do ser humano do sentimento de confiança, que serve de base para o estabelecimento de um nível mínimo de segurança ontológica, que Giddens precisa então recorrer à psicanálise e, baseando-se sobretudo em Balint e Winnicott, à noção de confiança básica, uma espécie de inoculação emocional que permite à criança estabelecer relações com os adultos e o mundo à sua volta.

“A confiança pode ser definida como crença na credibilidade de uma pessoa ou sistema, tendo em vista um dado conjunto de resultados ou eventos, em que essa crença expressa uma fé na probidade ou amor de um outro, ou na correção de princípios abstratos (conhecimento técnico). [...] Pode-se definir 'segurança' como uma situação na qual um conjunto específico de perigos está neutralizado ou minimizado. A experiência de segurança baseia-se geralmente num equilíbrio de confiança e risco aceitável." (GIDDENS, 2002, p.41-43)

É na noção de confiança básica que se articulam a percepção de si mesmo como um ser em separado da mãe, íntegro e capaz de sobreviver na sua ausência, e a própria experiência da partida e volta desse protetor. É a presença da mãe, como a figura capaz de garantir a sobrevivência do pequeno infante mesmo na sua ausência, que será a responsável por aquilo que Giddens descreve como uma inoculação emocional que protegerá o indivíduo de interrogações e ansiedades futuras.

É importante perceber que o que está em jogo aqui é a idéia de uma estabilidade do eu. É a manutenção dessa estabilidade que liga a experiência de presença/ausência da mãe - marcada pela certeza da sua volta que permite à criança suportar a inquietude de uma ausência que lhe tira sua principal referência de posicionamento no mundo - e os novos modos de viver a relação tempo e espaço, nos quais as relações aparecem desencaixadas, sem lugar, e o espaço esvaziado torna-se fantasmagórico e ameaçador para o sujeito. É, portanto, a concepção de um eu estável que sustentará a produção desse sentimento de segurança ontológica que, em outro lugar, Giddens chamará de formação de um casulo protetor (GIDDENS, 2002, p.11).

Se quisermos usar aqui uma terminologia mais próxima do jargão psicanalítico, é a construção de um eu (ego) forte, capaz de sobreviver à ausência do outro, ou de enfrentar a sua presença sem sucumbir a ela, que permitirá o 
relacionamento com o mundo e outros indivíduos, sendo a base necessária para a experiência da identidade.

O que estamos propondo é que não se pode pensar em confiança, por essa via, seguindo o pensamento de Giddens, sem recorrer a categorias como consciência, cálculo e escolha. Circunscrita à racionalidade moderna de fundo iluminista, tal leitura da experiência subjetiva acaba por colocar como matriz da insegurança e, portanto, da angústia, a dúvida, a incerteza, o desconhecimento e, por que não dizer, a inconsciência. Isso faz, por outro lado, com que a sensação de segurança - especialmente o que Giddens chama de "segurança ontológica”, como base possibilitadora da ação do indivíduo no mundo e como garantia mínima para sua sobrevivência enquanto sujeito — seja produzida pela certeza sobre o conhecimento, pela previsibilidade, portanto, do outro e de si mesmo.

\section{A AFIRMAÇÃO DA IDENTIDADE EM GIDDENS}

\section{E A CATEGORIA FREUDIANA DE EU}

Tal formação da confiança básica pode ser articulada à própria formação do eu e ao desdobramento do princípio de prazer em princípio de realidade tal como descritos por Freud, em particular no artigo sobre os dois princípios de funcionamento mental (FREUD, 1911/1999) e no artigo metapsicológico sobre a pulsão (FREUD, 1915/1999). É preciso, no entanto, destacar que na leitura apresentada por Giddens a ênfase aparece nos aspectos cognitivos de um processo de adaptação à realidade e no estabelecimento, pelo pequeno infante, de certa previsibilidade das relações entre o eu e o mundo, e vice-versa, enquanto que no texto freudiano a ênfase se encontra posta na economia das intensidades no psiquismo e na constatação de que o aspecto crítico não se dá pela estimulação externa sobre a totalidade do eu, ou self, mas pela irrupção da pulsão e pela necessidade de gestão do investimento libidinal em objetos sempre parciais.

Com base nessas proposições — as quais, no nosso entendimento, definem com razoável precisão tanto o que podemos experimentar cotidianamente como identidade, quanto o campo temático e determinadas marcas epistemológicas através das quais tal experiência se define discursivamente ${ }^{3}$ — pretendemos destacar, a partir do pensamento freudiano, alguns pontos críticos daquilo que chamamos, em articulação com a modernidade, de "perspectiva identitária”. Centraremos nossa argumentação numa discussão da categoria de eu, em primeiro lugar considerando sua articulação à noção de sujeito, em especial numa vinculação aos registros da razão e da consciência e, em segundo lugar, direcionando

\footnotetext{
${ }^{3}$ Para uma discussão mais extensa sobre a noção de identidade em Giddens, sobretudo na sua articulação com a experiência moderna e categorias como a de inteligibilidade, ver Cunha (2005).
} 
nossa discussão para o campo da metapsicologia, para destacar alguns aspectos econômicos dos modos de funcionamento daquilo que nos textos freudianos pode ser tomado como eu, antes mesmo da sua formalização como instância na segunda tópica (FREUD, 1923/1999).

O ponto central em nossa argumentação é que descrever a identidade como narrativa do eu, e aí ancorar a experiência de si e da relação com o outro, bem como os modos possíveis de construção dessa experiência, significa, de um ponto de vista psicanalítico, desconsiderar todo o campo problemático que se configura no pensamento freudiano em torno da noção de eu, além de implicar uma redução da experiência subjetiva à dimensão da consciência e da representação, vinculando-a a uma razão instrumental e a uma compreensão da categoria de sujeito que a invenção freudiana pôs em definitivo por terra.

O que nos parece fundamental é a necessidade de admitir que mesmo que tomemos a categoria psicanalítica de eu como topos da identidade no modelo de psiquismo desenhado por Freud, tal raciocínio não pode se dar de maneira simples ou imediata, mas, ao contrário, talvez nos obrigue a pensar, recorrendo à feiticeira metapsicologia, em outras formulações teóricas e outras formas da experiência clínica que dêem conta de novos modos e condições de possibilidade para a experiência subjetiva, diante dos quais o termo 'identidade', com toda a gama de sentidos e implicações que ele traz em sua genealogia, não será mesmo o mais adequado. Proposições teóricas e clínicas, enfim, que possam levar adiante a radicalidade do descentramento operado pelo pensamento freudiano na categoria de sujeito e que dêem conta desse modo a uma enunciação da experiência subjetiva na qual não esteja implicado este entrelaçamento entre o eu e a razão instrumental que está na base da narrativa identitária tal como descrita por Giddens.

Para isso, seria necessário, por exemplo, considerar que o eu, mais que uma totalização, pode ser pensado como função — totalizadora, integradora —, o que nos aproxima de uma leitura de Freud na qual elementos mínimos, como traços e mecanismos, ocupem um lugar central. Nessa direção, nos interessará de perto, por exemplo, o conceito de identificação (CUNHA, 1992).

Se nos situarmos numa perspectiva estritamente psicanalítica, é difícil considerar que haja uma narrativa linear do eu, ainda que destaquemos dessa narrativa seu caráter ficcional, porque não se pode pensar no eu em separado, como exterior a essa narrativa, se seguirmos a indicação de que o eu é uma organização, ou, de modo mais específico, “o setor organizado do isso” (FREUD, 1926[1925]/1999, p.93). A formulação de Giddens parece manter-se presa ao que podemos denominar 'filosofia do sujeito', à possibilidade de um eu/sujeito uno e íntegro, presente de algum modo desde o início e que seria, num segundo momento, aproximado ou capturado por um trabalho narrativo. Enquanto é mais próximo 
do pensamento freudiano pensar que é esse trabalho narrativo que procura, a cada segundo e de modo interminável, estabelecer para a experiência subjetiva essa unicidade e integridade, às quais reunimos sob o nome de 'eu'.

Isto porque é preciso levar em conta que uma das transformações operadas pela invenção da psicanálise foi a própria desconstrução da categoria de sujeito pelo seu descentramento. Para Birman (2003a), a transformação sofrida pela categoria de sujeito, bem como seu impacto concreto sobre as subjetividades, e, portanto, sobre o que pode ser pensado como identidade, foi muito radical, em especial a partir de fins do século XIX e da grande influência do pensamento freudiano, deixando as suas marcas no modelo identitário, e criando as condições para que possamos pensar, desde já, em outros modos de enunciação de si e de posicionamento diante do mundo e do outro. Tal descentramento do sujeito operado pela criação freudiana implicou numa desconstrução do cogito cartesiano e se deu em três movimentos: da consciência para o inconsciente; do eu para o outro; da representação para a pulsão.

O primeiro movimento, constituído a partir da descoberta do inconsciente, pôde "subverter os saberes sobre o psiquismo então instituídos: a psiquiatria e a psicologia" (BIRMAN, 2003a, p.17). Tais saberes, e sua evolução enquanto campos do conhecimento sobre o homem marcaram também a entrada em cena do que chamamos racionalidade moderna, num primeiro momento, pela crença absoluta nos poderes da razão e da consciência, que aparece, por exemplo, na figura do tratamento moral, o qual pretendia, partindo da nova descrição das doenças mentais como desvios da razão e transformações de ordem moral, instituir a cura por meio da recuperação do domínio da consciência e do pensamento fundando no cogito; num segundo momento, em especial no campo da psiquiatria, com as hipóteses da hereditariedade e da degenerescência, bem como pela busca incessante da causa biológica, somática, verificável de acordo com os novos parâmetros da ciência positiva.

Dessa forma, naquele momento, todo o vasto domínio da imaginação, vinculada à idéia de falso e da loucura, foi confinado no campo da desrazão e nos asilos, sucessores do antigo hospital geral e, como as prisões, versão moderna para o espaço de banimento, de exclusão do que não poderia ser incorporado à nova ordem.

"Neste contexto, a imaginação era constantemente considerada de maneira negativa, na medida em que não oferecia subsídios positivos para a elucidação do entendimento. Pelo contrário, aliás, pois os devaneios da imaginação afastavam a racionalidade do caminho reto do conhecimento. (...) Assim, a subjetividade era concebida como fundada apenas nos registros da consciência, do eu e do pensamento, pelos quais o critério da adequação do eu com os objetos 
do mundo era o único a ser destacado na leitura do psiquismo." (BIRMAN, 2003a, p.22-23)

Com a descoberta do inconsciente, de um campo outro de produção de sentido fora do alcance da consciência e do eu, embora capaz de produzir efeitos sobre o corpo, e com as conseqüentes formulações freudianas em torno de uma realidade psíquica na qual a fantasia e os afetos produzem efeitos concretos sobre a subjetividade, o eu e a consciência perdem seu valor prevalente para a vida anímica e, por outro lado, a sexualidade, os desejos e afetos ganham o centro da cena, tornando-se a fantasia uma potência fundada no poder da linguagem e das intensidades em circulação no psiquismo. A verdade sobre o sujeito já não encontra correspondência ou possibilidade de verificação na dita realidade material, acessível ao eu e à consciência, mas surge, muitas vezes de modo inesperado ou de forma enigmática, como nos sintomas e atos falhos, num emaranhado de fantasias compostas por traços psíquicos impregnados de intensidade e força.

A partir daí, torna-se muito difícil pensar, por exemplo, em uma "narrativa do eu", para usar uma das constantes e generalizadas definições da identidade presentes em Giddens, construída a partir da consciência e fundada na construção de uma linearidade entre passado, presente e futuro, que privilegia a previsibilidade e o progressivo ordenamento das informações sobre si mesmo de modo reflexivo, com base nas experiências passadas, numa espécie de ciência de si. O que a positivação da imaginação, pela via do reconhecimento da realidade psíquica, coloca em questão é exatamente esse poder instrumental do eu, que seria capaz, através de um ordenamento narrativo com base no pensamento racional, de dar conta da integração de toda a experiência subjetiva, ao mesmo tempo em que a adequa à realidade material. Com as formulações freudianas sobre o inconsciente e o reconhecimento de uma realidade psíquica capaz de produzir efeitos sobre a subjetividade, tal narrativa só seria possível a partir de uma permanente operação de exclusão dos conteúdos inaceitáveis pelo eu, supressão de afetos e produção de angústia. Tal modo de enunciação de si, sobre o controle exclusivo do eu, poderia ser assim considerado não um processo de subjetivação, mas sim uma forma de sujeição — o que seremos levados a discutir em seguida — , e se articularia então, mais uma vez, e não por acaso, à racionalidade repressiva que é, para Marcuse, a forma privilegiada de controle das subjetividades no capitalismo moderno (MARCUSE, 1969).

Retomando a leitura de Birman, o que se dá com o primeiro descentramento do sujeito produzido por Freud com a descoberta do inconsciente é a possibilidade, oposta, de que a imaginação e a livre circulação dos afetos possam produzir sentido, levando a novos modos singulares de subjetivação, nos quais, 
em vez do previsível, é o inesperado, o falho e o disruptor que atuam no centro da cena psíquica e da experiência subjetiva. A imaginação deixa de ser negativa e a realidade material já não deve ser a única referência na enunciação de si, da mesma forma que, para além do pensamento racional, o que é sentido e muitas vezes não chega sequer a ser posto em palavras, todo o campo dos sentimentos e desejos, passa a ser reconhecido como fundamental na experiência que cada um pode ter de si mesmo e da relação com o outro.

O segundo movimento, na direção de uma desconstrução do sujeito edificado a partir da razão e da consciência, deslocou tal sujeito do eu para o outro, colocando-o fora de si. Tal movimento começa a se desenhar a partir do lugar central que passa a ter a categoria de interpretação, no momento em que o sentido inconsciente precisa ser construído a partir das suas formações - o sintoma, o ato-falho, a fantasia — e se revela no encontro com o outro, sendo aqui paradigmático o modelo do próprio tratamento psicanalítico, no qual a produção de novos sentidos e o reordenamento subjetivo se dão não apenas na suspensão do eu que se produz no paciente com o método da associação livre, mas sobretudo no encontro dessa errância imaginativa com outra errância e outra suspensão do controle do eu, que deve se dar no analista pela atenção flutuante. É no encontro paradoxal de dois eus ausentes que novos sentidos podem se fazer presentes. Nessa perspectiva, a subjetividade precisa ser tomada não como integridade, mas, fragmentária e dispersa, em toda a sua potência (BIRMAN, 2003a).

O deslocamento do eu para o outro encontra o seu sentido mais pleno a partir da introdução por Freud da noção de narcisismo, no texto de 1914 (FREUD, 1914/1999). Como indica Birman, é nesse momento que o eu perde em definitivo qualquer possibilidade de autonomia ou de soberania sobre o psiquismo, na medida que se formula sua dependência em relação aos investimentos libidinais. Tal eu, sexualizado, investido, passa a ser também dependente das intensidades em circulação no psiquismo, tendo assim prejudicada sua capacidade instrumental. Deixa de ser originário e passa a ser constituído numa história de amor e ódio vivida com um outro privilegiado (BIRMAN, 1999, p.64) que lhe empresta sua própria imagem como condição de possibilidade para a integração desse eu (LACAN, 1966). Se antes o eu, com suas pulsões de autoconservação e seu princípio de realidade, poderia governar uma adequação da experiência subjetiva aos parâmetros de uma realidade material, verificável, agora também ele se encontra perdido numa trama de fantasias e desejos, submetido à força da pulsão, disperso e fragmentário. A idéia de um inconsciente que pudesse ser ordenado em uma narrativa racional, obedecendo aos padrões vigentes de inteligibilidade a partir de um trabalho de deciframento operado por um eu soberano, também se torna cada vez menos viável. 
Assim, também os ideais de unicidade, integração e permanência implicados na noção de identidade, seja ela originária ou a ser construída, tornam-se cada vez mais distantes. Com esse novo deslocamento operado na categoria de sujeito pelo pensamento freudiano, também as formas de relacionamento com a alteridade se transformam, de modo que o reconhecimento de si e o reconhecimento do outro passam a ser interdependentes, produzindo um conflito permanente que o simples domínio do outro e sua destituição do lugar de sujeito, como no modelo colonial, não podem resolver.

Se retomarmos, mais uma vez, e agora de forma bastante sintética, a formulação da identidade em Giddens que apresenta a identidade como a narrativa construída pelo eu, para dar conta da sua integridade e permanência como sujeito ao longo do tempo, garantindo a adequação desse eu às exigências da realidade e podendo ser enunciada pela consciência, o que temos com o primeiro movimento freudiano é que tal enunciado consciente não seria possível a não ser pelo recalque permanente das fantasias inconscientes; com o segundo movimento é a idéia de um eu íntegro e contínuo, da ordem da razão e da consciência, que perde o sentido; com o terceiro movimento, o deslocamento do sujeito da representação para a pulsão, é a própria idéia de narrativa que é colocada em questão quando se trata de dar conta da experiência subjetiva.

Para Birman, com a introdução da noção de pulsão de morte, uma pulsão sem representação, pura força em movimento, produtora permanente de ruptura e dispersão, o eixo da representação não pode mais ser capaz de integrar a experiência do sujeito na relação consigo mesmo e com o outro.

Sendo o psiquismo pensado como um confronto interminável de forças, que um trabalho permanente de ligação conduzido pelo investimento erótico do outro tenta dar conta, sem que possa alcançar em qualquer momento um sucesso definitivo, fica inviabilizada qualquer submissão da experiência subjetiva a categorias como previsibilidade, controle e inteligibilidade. Tal experiência seria concebida, a partir desse momento, como intrinsecamente imprevisível, incontrolável e, no mais das vezes, ininteligível, e os esforços de estabelecimento de uma ordem da previsibilidade, ou da inteligibilidade, possibilitadora por sua vez do controle e do domínio, somente se fariam possíveis no momento em que tal subjetivação, de modo paradoxal, se transformasse em sujeição.

Nesse percurso multidirecional, algumas das grandes conquistas do pensamento iluminista, bases para a racionalidade dominante a partir da modernidade, são postas em questão, como as idéias de sujeito, verdade e representação. Com isso, a noção de identidade, tal como a vimos apresentando até agora, e a própria categoria de indivíduo sobre a qual deve se sustentar qualquer teoria ou esforço identitário, revela-se frágil no seu caráter instrumental, como possibilidade de integração da experiência subjetiva por meio da adequação a uma realidade dita 
objetiva, submetida aos parâmetros da racionalidade estabelecidos a partir da chamada filosofia do sujeito.

Podemos ainda considerar outro percurso possível para a crítica da perspectiva identitária, no qual será fundamental essa tomada em consideração de uma dimensão econômica do psiquismo, na qual é o jogo de intensidades afetivas que se colocará no centro da experiência de si mesmo e da relação com o outro.

Podemos, nesse sentido, iniciar pela consideração da categoria de ansiedade, que no texto de Giddens aparece vinculada à insegurança, enquanto na proposição freudiana se articularia mais precisamente ao desamparo (FREUD, 1926[1925]), o que nos obriga, por exemplo, a pensar em que medida o desamparo freudiano pode ser apaziguado pelo conhecimento do mundo ou mesmo pelo estabelecimento de laços de confiança, ainda que se trate aí das figuras parentais. Tal formulação, aliás, nos aponta um outro problema que é a tomada do infantil por Giddens apenas em seu sentido cronológico, engendrando relações de causa e efeito, enquanto podemos pensar, numa outra direção, na aproximação entre o infantil e o primário (FREUD, 1911/1999), aquilo que insiste ao longo e a cada momento de nossa existência, se revela a marca diferencial do inconsciente e se articula ao livre jogo das intensidades na forma de energia não ligada, exigindo como contrapartida o trabalho de ligação por meio do qual se dará não só a formação do eu, mas a própria constituição do aparato (BIRMAN, 2003b). O que aparece, por exemplo, no modelo de formação do eu e de diferenciação sujeito/objeto a partir da passagem de um eu-realidade originário a um eu-prazer e, em seguida, a um eu-realidade definitivo (FREUD, 1915/1999), processo que se articula à própria diferenciação de um princípio de realidade (FREUD, 1911/1915) e mais uma vez aos modos de regulação das intensidades pelo trabalho psíquico de ligação (LAPLANCHE, 1982, p.347-350).

Na experiência identitária, tal como lemos em Giddens, é o trabalho de síntese, empreendido sob a forma de uma narrativa do eu que costura passado, presente e futuro na direção da previsibilidade e controle dos eventos, o que procura dar conta da angústia, sendo esta articulada então à insegurança e fundada na falha desse controle. Assim, a superação da insegurança e o apaziguamento da angústia devem ser buscados no aperfeiçoamento das funções de controle a partir do conhecimento sobre a realidade e sobre o outro, o que, nos relacionamentos amorosos, por exemplo, implica em tornar esse outro previsível e passível de incorporação a essa narrativa de si (GIDDENS, 1993).

Em contraste, na lógica freudiana não há como separar a produção da angústia do próprio funcionamento da defesa, que ao menos em princípio proporcionaria ao eu o sentimento de segurança. É certo que a idéia de angústia como a de uma indicação de um perigo para o eu é tributária do pensamento 
de Freud. A sutileza aí está em perceber que a construção do eu está imbricada à produção desses “perigos”.

Por fim, é importante considerar, ainda, que se na perspectiva de Giddens a realidade aparece como algo objetivo e a defesa identitária se dá sempre como adequação a essa realidade - cognoscível, previsível, verificável, de acordo com o próprio modelo da ciência positiva - no modelo freudiano as operações defensivas, vinculadas à construção do eu e à gestão da angústia, cuja fonte primária pode ser localizada no excesso pulsional, implicam, ao contrário, a perda do contato com a realidade que, de modo aparentemente paradoxal, podemos vincular, complicando um tanto mais as coisas, ao empobrecimento erótico, a uma redução da libido.

Ou seja, o modelo de relação eu-e-mundo que sustenta a perspectiva identitária tal como Giddens a explicita, ao mesmo tempo que se mantém tributário da filosofia do sujeito e do primado de uma razão instrumental fundada na consciência, simplifica a compreensão psicanalítica da vida emocional e desconsidera a radicalidade da invenção freudiana e toda a gramática inconsciente fundada no jogo mortífero das intensidades que invadem e constituem o aparelho psíquico.

Recebido em 6/12/2006. Aprovado em 25/4/2007.

\section{REFERÊNCIÄS}

BIRMAN, J. (1999) Mal-estar na atualidade. Rio de Janeiro: Civilização Brasileira. (2003a) Freud e a filosofia. Rio de Janeiro: Jorge Zahar Editor. . (2003b) Corpo e formas de subjetivação em psicanálise. Disponível em: http://www.estadosgerais.org. Acesso em: 21/06/2006.

BAUMAN, Z. (2002) “Identité et mondialisation”, in MICHAUD, Y. (org.). L'Individu dans la societé d'aujourd'hui. Paris: Odile Jacob — Université de tous les savoirs, v.8.

CHEMAMA, R. (org.) (1995) Dicionário de psicanálise. Porto Alegre: Artes Médicas.

CUNHA, E. L. (1992) “Imagem e semelhança — metapsicologia da identificação”. Dissertação de Mestrado, Programa de Pós-Graduação em Teoria Psicanalítica, Universidade Federal do Rio de Janeiro.

. (2000) Uma interrogação psicanalítica das identidades. Cadernos do CRH, n.33, Salvador: UFBA, p. 209-228.

. (2005) "Indivíduo singular plural: uma crítica psicanalítica das identidades”. Tese de Doutorado em Saúde Coletiva, IMS, Universidade Estadual do Rio de Janeiro.

DUMONT, L. (2000) Individualismo. Rio de Janeiro: Rocco. 
ERIKSON, E. (1968/1987) Identidade, juventude e crise. Rio de Janeiro: Guanabara.

FREUD, S. (1999) Obras completas. Buenos Aires: Amorrortu.

(1911) "Formulaciones sobre los dos principios del acaecer psíquico", v.XII, p.217-231.

(1914) “Introducción del narcisismo", v.XIV, p.65-98.

(1915) "Pulsiones y destinos de pulsión”, v.XIV, p.105-134.

(1919) “Lo Ominoso”, v.XVII, p.217-251.

(1923) "El yo y el ello", v.XIX, p.1-66.

(1926[1925]) “Inhibición, síntoma y angustia”, v.XX, p.71-164.

GIDDENS, A. (1991) As conseqüências da modernidade. São Paulo: Editora Unesp.

. (1993) A transformação da intimidade. São Paulo: Editora Unesp. (2002) Modernidade e identidade. Rio de Janeiro: Jorge Zahar.

HALL, S. (2003) A identidade cultural na pós-modernidade. Rio de Janeiro: DP\&A.

KAUFMANN, P. (1996) Dicionário enciclopédico de psicanálise. Rio de Janeiro: Jorge Zahar.

LACAN, J. (1966) "Le stade du miroir como formateur de la fonction du Je”, in Écrits. Paris: Seuil.

LAPLANCHE, J.; PONTALIS, J-B. (1982) Vocabulário da psicanálise. São Paulo: Martins Fontes.

MARCUSE, H. (1969) Eros e civilização. Rio de Janeiro: Zahar Editores.

ROUDINESCO, E.; PLON, M. (1998) Dicionário de psicanálise. Rio de Janeiro: Jorge Zahar.

Eduardo Leal Cunha edulc@oi.com.br 